This item was submitted to Loughborough's Research Repository by the author.

Items in Figshare are protected by copyright, with all rights reserved, unless otherwise indicated.

\title{
A systems ergonomics analysis of the Maidstone and Tunbridge Wells infection outbreaks
}

PLEASE CITE THE PUBLISHED VERSION

\section{VERSION}

SMUR (Submitted Manuscript Under Review)

LICENCE

CC BY-NC-ND 4.0

REPOSITORY RECORD

Waterson, Patrick. 2019. "A Systems Ergonomics Analysis of the Maidstone and Tunbridge Wells Infection Outbreaks". figshare. https://hdl.handle.net/2134/5948. 
This item was submitted to Loughborough's Institutional Repository (https://dspace.lboro.ac.uk/) by the author and is made available under the following Creative Commons Licence conditions.

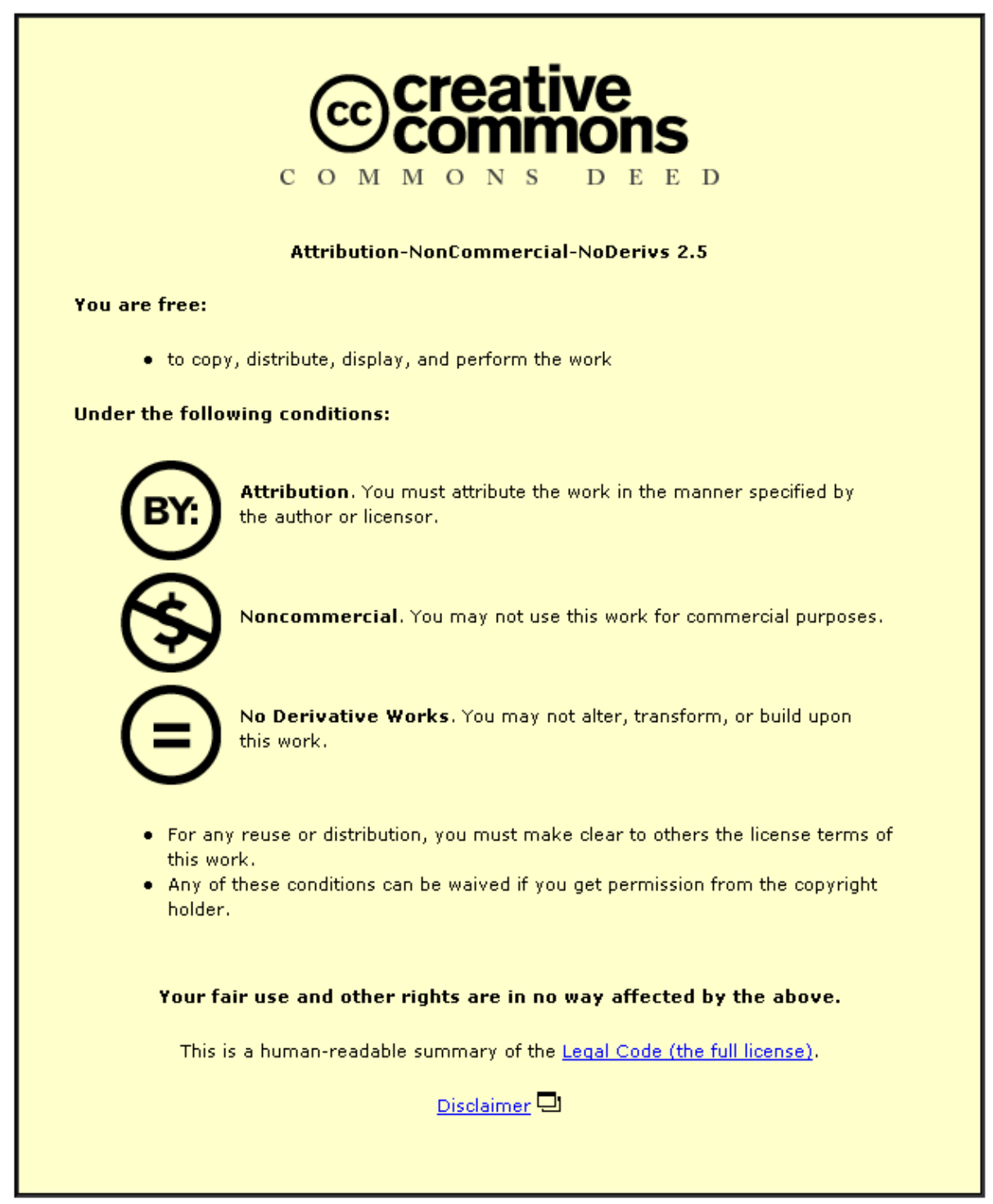

For the full text of this licence, please go to: http://creativecommons.org/licenses/by-nc-nd/2.5/ 


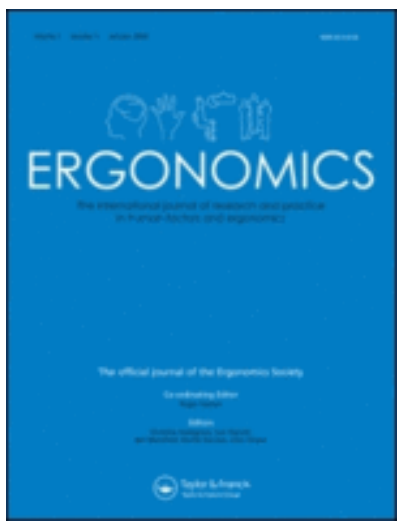

\section{A Systems Ergonomics Analysis of the Maidstone and Tunbridge Wells Infection Outbreaks}

\begin{tabular}{|r|l|}
\hline Journal: & Ergonomics \\
\hline Manuscript ID: & TERG-2008-0272.R1 \\
\hline Manuscript Type: & Original Article \\
\hline $\begin{array}{r}\text { Date Submitted by the } \\
\text { Author: }\end{array}$ & 12 -May-2009 \\
\hline Keywords: & $\begin{array}{l}\text { Work organisation < Organisational Ergonomics, organisational } \\
\text { change < Organisational Ergonomics, health care ergonomics < } \\
\text { Application Domains, socio-technical systems < Organisational } \\
\text { Ergonomics, complex systems < System Performance }\end{array}$ \\
\hline &
\end{tabular}

\section{(s) ScholaroNE" \\ Manuscript Central}


6

7

\section{A Systems Ergonomics Analysis of the Maidstone and Tunbridge Wells} Infection Outbreaks

\author{
Patrick Waterson ${ }^{1}$ \\ Department of Human Sciences \\ Loughborough University \\ Loughborough, LE11 3TU, \\ United Kingdom
}

Address for correspondence:

Dr Patrick Waterson

Department of Human Sciences

Loughborough University

Loughborough, LE11 3TU,

United Kingdom.

Tel: 01509228478

Fax: 01509223940

$\overline{{ }^{1} \text { Email: p.waterson@lboro.ac.uk. }}$ 


\begin{abstract}
This paper describes a systems ergonomics analysis of the recent outbreaks of Clostridium difficile which occurred over the period 2005-07 within the UK Maidstone and Tunbridge Wells NHS Trust. The analysis used documents related to the outbreak, alongside the construction of a system model in order to probe deeper into the nature of contributory factors within the Trust. The findings from the analysis demonstrate the value of looking further at cross-level and whole-system aspects of infection outbreaks. In particular there is a need for further study of the causal relationships that exist between hospital management and clinical management levels within the system. Finally, the paper discusses ways forward and strategies that could adopted in order to limit the outbreak of hospital-related infections and shape future research.
\end{abstract}

\title{
Statement of Relevance for Ergonomics Practice
}

The approach used for the system analysis described in the paper could be used by health care practitioners and ergonomists to probe deeper into the causes of infection outbreaks and to extend the scope of interventions aimed at preventing their occurrence.

\section{Keywords}

Health Care Ergonomics; Complex Systems; Sociotechnical Systems; Work Organisation; Organisational Change 
Figure 1 about here

The subject of hospital infection control and prevention has recently become the subject of much media attention in the UK (The Guardian, 2007; BBC Panorama, 2008). A number of high profile hospital outbreaks within the UK involving bacterium such as Clostridium difficile (C. diff.) and MRSA (Methicillin-resistant Staphylococcus aureus) have raised infection control into a central priority for the UK NHS and other health care systems worldwide (Allegranzi et al., 2007). Much of the debate so far has concentrated on improving hygiene within hospitals (e.g., hand washing, deep cleaning), very little research has been conducted on the wider behavioural, social and organisational factors that may also determine infection control outbreaks (Griffiths, Renz and Rafferty, 2008). Hospitals are complex sociotechnical systems, spanning a range of technologies (e.g., medical devices, electronic records), actors (e.g., clinicians, health care professionals) and aspects of physical design (e.g., wards and operating theatres) (van Maanen and Barley, 1985). Within systems ergonomics Rasmussen (1997) has provided a modelling framework for understanding the dynamic interaction between these types of components within a large-scale sociotechnical system. The framework consists of two main components: a structural hierarchy describing the various actors; and, contextual factors influencing the activities of the actors (figure 1).

Vicente and Christoffersen (2006) have used the modelling framework to identify the lessons learnt from the May 2000 outbreak of E. coli which occurred in Walkerton, Canada. Their analysis identified a set of contributing factors that led up to the Walkerton outbreak. These included decisions made at governmental levels (e.g., privatisation initiatives), the action of actors within the system (e.g., failures to take water samples), as well as equipment failures (e.g., shallow water wells).

The aim of the present paper is to examine in detail an example of a series of infection outbreaks as they occurred within a complex sociotechnical system from the 
perspective of systems ergonomics. The example is drawn from the outbreak of the bacterium Clostridium difficile which occurred between 2005 and 2007 in the Maidstone and Tunbridge Wells NHS Trust. In particular, the paper aims to address the following objectives:

- To explore the potential of using systems ergonomics in order to analyse and explain the causes of the outbreaks;

- To consider the relationships that exist within and between system levels and use these to suggest new ways of examining causal dependencies and linkages;

- To consider the implications of a systems analysis in terms of recommendations for future research and practice within infection control.

In section 2 the methodology and steps used to analyse the outbreaks and perform the systems analysis are described. Section 3 describes the background to the outbreak alongside a set of contributory factors that have been highlighted in the report produced by the UK Healthcare Commission in 2007. Section 4 of the paper describe the outcomes of the systems ergonomic analysis. The final section (section 4) describes strategies that could be used in order to help prevent further outbreaks occurring, and discusses the findings within the context of previous and future research within infection control.

\section{Methodology}

Very few explicit guidelines exist for carrying out systems analyses within human factors and ergonomics. Rather than fixed or definitive methods of analysis, researchers have in the past adopted a number of methods and techniques, often in parallel (e.g., Singleton et al., 1967; Optner,1973; Beishon and Peters, 1976). More recently, researchers have often used their own methodologies, conceptual frameworks and approaches to analyses complex systems (e.g., the STAMP approach - Leveson et al., 2009; the various methods described by Hollnagel et al., 2006 in their description resilience engineering). In this paper the following procedure and steps were used for carrying out the systems analysis and covered an initial phases of system description followed by analysis: 


\section{System description}

(1) Document analysis - this involved reading the various reports that have been written concerning recent infection outbreaks in the UK NHS. The main focus was on the Health Commission's main report published in 2007, but also involved consultation of other relevant documents (e.g., Healthcare Commission, 2006, 2008). The analysis took the form of summarising the main contributory factors leading up to the outbreak at Maidstone and Tunbridge Wells. In particular, examples of human and organisational factors covering a range of system-related dimensions were extracted from the report (e.g., relationships between external organisations, management, group and individual behaviour, workplace design and equipment).

(2) Construction of a timeline of events - based upon the 2007 report the main events leading up to the outbreaks were summarised (table 1).

\section{$\underline{\text { System analysis }}$}

(3) System modelling - this involved mapping the contributory factors onto a systems framework, in this case the risk management framework described by Rasmussen (1997). The mapping task also involved modifying the risk management in order to fit the specific details of the outbreak and coverage of the main system components (see figures $2 \mathrm{a}, \mathrm{b}$ and $\mathrm{c}$ ).

(4) The final stage of the analysis involved examining the resulting system model in order to propose possible causal linkages and relationships between specific system levels (e.g., hospital management and clinical management levels), as well as links and relationships which may have applied to the system as a whole.

\section{System description of the Clostridium difficile outbreak in the Maidstone and Tunbridge Wells NHS Trust}

The description and analysis of the outbreak is primarily based upon the report produced by the Healthcare Commission (HC) (2007). In addition, other sources of documentary information concerning the outbreak were consulted, these included previous reports of outbreaks (e.g., Healthcare Commission, 2006), as well as other literature within the area of health care-related infection control (e.g., National Audit Office, 2000; Duerden, 2008; Healthcare Commission, 2008). 


\subsection{Background to the outbreak and timeline}

During the period between April 2004 and September 2006 an estimated 90 people died at the Maidstone and Tunbridge Wells NHS Trust as a result of becoming infected with the Clostridium difficile (C.diff.) bacteria (Healthcare Commission, 2007, p.5). C. diff. is the major cause of serious bacterial infectious diarrhoea acquired in hospitals in the UK and is particularly resistant to drying, chemical disinfectants and alcohol. The number of cases of $C$. difficile and reported deaths has increased within the UK in the last few years and similar outbreaks have occurred at other hospitals (e.g., Stoke Mandeville - Healthcare Commission, 2006). Recommendations for the prevention of the spread of the bacteria include: the timely isolation of known and suspected cases; the control of antibiotics; the application of high standards of hygiene; and, the restriction of the movements of patients. The main events at the Maidstone and Tunbridge Wells NHS Trust are summarised in table 1.

\section{Table 1 about here}

\subsection{Report findings: summary of contributory factors}

The Healthcare Commission (2007) (HC, 2007) report identified a number of factors that contributed to the outbreaks that occurred with the trust. The following sections present a selection of the main findings from the report.

\subsubsection{The role of external organisations}

The external body responsible for the National Health Service as a whole is the UK government. Aside from developing overall NHS strategy and policy, the government is also responsible for allocating budgets and setting financial and service level targets (e.g., maximum waiting times for operations, hospital stays). Within the report both the setting of targets and financial pressures on NHS trusts are mentioned as background, contributory factors that had an impact on the day-to-day operation of the Maidstone and Tunbridge Wells trust. In particular, the report mentions the need for trust board members and managers to meet throughout targets for the use of beds. 
Higher bed occupancy meant that there was less time for the cleaning and a higher probability of transmission of infection between patients (HC, 2007, pp.69-70). The need to meet financial targets such as spending on equipment and buildings also placed pressure on the trust to cut back in areas that impacted upon infection control such as financing for new buildings and isolation areas. The issue of finance and targets were singled out in the report as one common factor in both the Maidstone and Tunbridge Wells and Stoke Mandeville (Healthcare Commission, 2006) infection outbreaks.

Aside from the government infection control within the UK NHS is regulated by a number of other bodies. The creation of the Health Protection Agency (HPA) in April 2005 coincided with the first outbreak at the trust. The remit of the HPA is to provide advice and support to NHS, local authorities and other agencies with regard to public health issues. One part of the HPA, the health protection unit (HPU), is to support organisations in their management of infections. The report highlights that this caused some confusion within the trust at the time of the outbreaks as the expectation was that the HPU could give provide guidance covering the supervision and monitoring of infection control. Similar problems were encountered within the much larger Strategic Health Authority (SHA), the report mentions that until recently the SHA were more focused on outbreaks of other healthcare associated infections (e.g., MRSA), partly because these were at the time of the outbreaks one of the national priority to which performance targets were attached.

\subsubsection{Management of the trust}

The report describes a catalogue of problems and failures associated with the management of the trust at the time of the outbreaks. In addition, other factors contributed to the problems faced by managers and trust board members, these included high turnover of senior managers over the period of the outbreaks and a management style that was described in the report as "reactive, with frequent changes of direction" (HC, 2007, p. 8).

In terms of clinical risks and incidents, the report describes how management strategy in general "had been fragmentary and poorly understood" (HC, 2007, p. 77). In March 2003 the Department of Health issued guidance on constructing a risk assurance 
framework, part of which involved reducing hospital-based infections. Despite this no mention was made of $C$. diff. infections until 2006/7 (HC, 2007, p. 77). Similar problems applied to systems in place that were designed to learn about and respond to clinical incidents. The reports from an internal group set up within the trust in order to analyse complaints, claims and incidents highlight, amongst others, the following issues: the unsatisfactory nature of some "escalation" areas (areas temporarily set up to deal with infected patients), areas which were opened to take admissions; the effect the accident and emergency (A\&E) target had on the quality of care; poor quality handover and transfer to wards from A\&E; concerns about staffing levels, and bank staff managing wards on some shifts.

The style of leadership within the trust and the overall management culture were criticised in the report. Many staff described the leadership of the chief executive as being "autocratic" or "dictatorial" (HC, 2007 p. 91). The report concluded that the person appointed as director of infection prevention and control had "no real understanding of the role at the outset" (HC, 2007, p. 5). Turnover of managers and directors was high. Between September 2002 and September 2006 five people attended the board in five roles as director or director of finance (HC, 2007, p. 91). Despite weekly meetings the report concludes that there was little evidence of managers working collaboratively to address problems (HC, 2007, p. 91). Managers were often under considerable stress and in fear of losing their jobs (HC, 2007, p. 92). Likewise most staff were afraid to speak out and raise concerns about what was happening within the trust.

Amongst staff, as well as some of those in senior positions within the trust, the overwhelming priority of senior managers was seen to be finance and the need to meet national targets (e.g., A\&E targets). Financial restrictions placed a heavy burden upon levels of bed occupancy, staffing levels and the availability of equipment (HC, 2007 , p. 93). The need to satisfy targets was seen as the primary reason why patients were moved around so often, thereby increasing the risk of infections spreading. In addition, poor handover between wards worsened the situation.

Finally, the trust's management of staffing is criticised heavily within the report in several places. The number of nurses working on wards had fallen since the period 
2002/03. and at the same time the number of beds had also reduced. In 2006/07 the number of nurse per bed was 1.52, the same number as in 2003/04 (HC, 2007, p. 82). trust managers had not carried out a comprehensive review of staffing levels or a determination of minimum staffing levels. Although the board noted in September 2006 that low staffing numbers posed a risk when managing highly-dependent patients with $C$. diff., they had a not earlier analysed poor care in relation to staffing levels to see if there was a connection (HC, 2007, p. 83).

\subsubsection{Clinical management on the hospital wards}

A review of the case notes of 50 patients who had died having had $C$. diff. found that in $80 \%$ of the case, at least one element of the clinical management, or monitoring of C. diff at ward level was unsatisfactory (HC, 2007, p. 4). A number of elements are mentioned, including: infrequent reviews of patients by doctors; lack of systematic monitoring as to whether or not a patient was recovering from $C$. diff; and, failure to change antibiotic treatment when a patient failed to respond to the initial treatment (HC, 2007, p. 4). Delays in starting treatment occurred on the wards, mostly because there was a delay in sending samples for analysis (HC, 2007, p. 33). The report found that there was little evidence that once $\mathrm{C}$. diff. had been diagnosed that patients were monitored for severe signs of the infection (HC, 2007, p. 34). In other cases, it was clear that diagnoses were either not considered or had been missed. In $34 \%$ of the cases reviewed, medical records did not indicate that a regular review of $\mathrm{C}$. diff had taken place (HC, 2007, p. 38). The management of fluids and nutrition on the wards was also inconsistent. In $36 \%$ of the case reviewed there was evidence of poor fluid management and in 34\% nutritional needs had not been assessed or managed (HC, 2007, p. 38).

\subsubsection{The infection control team}

The role played by the infection control team within the trust was a complex one and one made difficult by problems relating to accountability, the amount of resources available to them and their ability to function as a team. The arrangements for accountability were not clear (HC, 2007, p. 54). Infection control nurses were accountable to the director of nursing, the pathology manager held the budget for these nurses, but did not consider that he had any management responsibly for infection control. Similarly, the clinical director of pathology was not aware of any 
responsibility for infection control. The person in charge of budgets for pathology, the director of operations, did not consider that he had management responsibility for the team. Not until September 2006 did the trust take steps to clarify the management of the team (HC, 2007, p. 51).

The resources available to the team were limited. It was noted in November 2003 that the team was understaffed with one team having to cover all three hospitals in the trust (HC, 2007, p. 51). Inevitably, the team was overstretched and at times this mean that they fell behind on their audit work. Absences due to annual leave and sick leave were not always compensated through the use of locum cover. The degree to which the infection control team worked well together and functioned as a team is criticised in the report (HC, 2007, pp. 53-54). The microbiologists in the team were seen as helpful by staff, but not natural leaders or champions for infection control. They did not regularly visit wards and were hard to contact. In addition, the advice they gave was often conflicting and inconsistent. The infection control nurses by contrast, visited ward regularly and tended to act as a link between ward staff and microbiologists. However, the report also notes that working relationships between nurses and microbiologists were not always close or supportive. Meetings of the infection control committee were infrequent and clinical staff such as senior nurses and consultants were often not present at the meetings (HC, 2007, p. 54).

\subsubsection{Equipment and hygiene}

Hygiene practices within the trust and the state of hospital buildings contributed a great deal to the outbreaks. Wards, bathrooms and commodes were not clean and patients had in some cases to share equipment (e.g., Zimmer frames) which were not cleaned before use (HC, 2007, p. 4). The infection control team were keen to isolate patients once they had been identified as $C$. diff. cases, however the scarcity of side rooms made this difficult. As a result many patients before and after the outbreaks were kept on open wards. The design of buildings and their age meant that many wards did not have sufficient space for storage or the provision of hand basins in utility rooms. The buildings in the trust were generally old or in a poor state of repair and when they were first opened did not have adequate cleaning and laundry services (HC, 2007, p. 6). 
Figure 2 (a) here

The upper or macro-levels of the system in figure 2 (a) (government, regulatory, trust governance), can be regarded as representing institutional and organisational influences on the system as a whole. Similarly, lower or micro-levels (e.g., hospital and clinical management, equipment and buildings), represent influences arising through the day-today work of staff and the environment in which they worked. One way in which the outbreaks can be explained is to analyse in further detail the relationships and contributory factors that exist across macro- and micro-levels system levels (Genaidy et al., 2008). Within the field of organisational behaviour, Hackman (2003) has suggested that researchers adopt the strategy of crossing levels, using what he terms "bracketing" analysing constructs or influencing factors that exist in two or more system levels. Within ergonomics, Karsh (2006) has advocated something similar in his use of the term "mesoergonomics" which he defines as "an open system approach to the development of macroergonomic theory and research whereby the relationship between variables in at least two different levels or echelons are studied" (p. 3). Finally, House et al., (1995) suggest that so-called "meso-level" analyses should also address the issue of "isomorphic" constructs within the system. These types of constructs involve analysing the whole system in order to assess: "the degree to which the constituent components of a phenomenon and the relationships among the components are similar across levels of analysis" (House et al., 1995, p. 87). 


\subsection{Cross-level relationships}

A summary of some of the possible cross-level relationships that contributed to the outbreaks are shown in figure 2 (b).

Figure 2 (b) here

At the regulatory, trust governance and hospital management levels of the system, bedoccupancy and other targets placed many individuals under a great deal of pressure. This pressure in itself may have led them to make poor decisions, and in some cases to prioritise bed occupancy rates at the expense of the risk of an infection outbreak. Previous research on the influence of targets on management decision-making in health care tends to be equivocal. Bean and Hood (2006) for example, show that the impact of satisfying a specific target (e.g., hospital waiting times) has not been analysed in terms of how this influences other related services (e.g., quality of care). Within the trust it is likely that targets exerted considerable pressure on the system as a whole and this pressure filtered down various levels of the system. It is possible that the drive to comply with these targets increased the likelihood of an adverse event or set of events taking place at some stage within the trust (West, 2000).

A separate report by the Healthcare Commission (2008) examined the underlying causes of serious failures in NHS health care providers and identified large-scale organisational processes such as mergers and poor change management procedures as common factors. The outbreaks within Maidstone and Tunbridge Wells, as well as the earlier outbreak at Stoke Mandeville Hospital (Healthcare Commission, 2006), took place against the background of large-scale organisational mergers. Previous research on the impact of mergers on employees has shown that decreased employee motivation and higher staff turnover are frequent outcomes (Cartwright and Cooper, 1993), alongside poorer organisational performance and productivity (Kiessling, Harvey and Heames, 2008).

In terms of the overlap between hospital and clinical Management system levels it is 
clear that the actions of senior managers were identified as significantly contributing to the failure to prevent and deal with the outbreaks. The link between management, human resource management (HRM) practices and work performance outcomes has been investigated in detail in the last few years. Wood and Wall (2002) for example, reviewed evidence that suggests there is a link between high-involvement HRM practices and employee productivity. High involvement HRM practices typically include empowering employees to make their own decisions and the presence of selfmanaged teams. The review showed that there these types of practices in organisations do tend to increase levels of employee productivity. Similar effects have been shown between HRM practices and measurements of safety outcomes (e.g., number of adverse events). In general, there is strong evidence to suggest that aspects of management behaviour partially shape and determine the culture of safety within organisations (e.g., Zohar, 2000). Within health care specifically, West et al. (2002) carried out a largescale survey of the relationship between HRM practices and general in-hospital mortality. The survey showed some aspect of high involvement HRM were associated with lower mortality rates after adjustment for patient and hospital characteristics.

With regard to the interaction between clinical management and equipment and buildings system levels, the report identifies understaffing and general lack of resources, both human and in terms of equipment, as playing a major part in the outbreaks. Staffing ratios, levels of staff morale and inadequate facilities almost certainly contributed to the problem of containing the spread of infection on the wards. In general, the research literature provides some evidence that lower levels of staffing increase the likelihood of infections occurring. Hugonnet et al. (2004) examined the numbers of nursing staff and staff downsizing relative to infection levels. The researchers found an inverse relationship between staff downsizing and the rate of hospital-based infection. Little research has been conducted on the impact of job satisfaction/morale on hospital infection levels, however, work in other domains (e.g., manufacturing and service industries) suggests that lower levels of satisfaction are clearly linked to lower levels of job performance, as well as being influenced by other environmental factors (Parker and Wall, 1998).

\subsection{Whole system relationships}

The nature and patterns of decision-making and the capacity for organisational learning 
within the trust might be singled out as potential "isomorphic" constructs that influenced the outbreaks and the way in which they were subsequently managed figure 2 (c).

Figure 2 (c) here

Aside from the way in which senior managers behaved at the trust, the questions still remains as to why they ignored, or at least failed to realise the seriousness of the outbreaks and their consequences. Many of the managers interviewed in the original Healthcare Commission report reported that they were aware of how serious the situation had become within the trust, but were powerless to do anything about it. One possible explanation is what Vaughan (1996) in her study of the Challenger shuttle disaster termed the "normalization of deviance"; namely, that managers over time began to accept and take for granted the level of infection risk within the trust. Only after the level of risk built up to a point where it was effectively out of control, did they begin to realise the gravity of the situation.

It might be conjectured that the behaviour of clinicians and other health care professionals across other system levels shares similarities with those of senior managers and trust board managers. Many individuals at ward level were aware of the levels of poor hygiene and inadequate patient monitoring practices, but saw no way to improve the situation. Weick and Sutcliffe (2003) analysed data from the Bristol Royal Infirmary Report (Department of Health, 2001) and concluded that hospital staff became locked into particular lines of action or behaviour where they "search for confirmation that they are doing what they should be doing" (p. 73). These so-called “cultures of entrapment" inhibit an organisation's ability to break out of patterns of behaviour that over time can lead to adverse outcomes. Other researchers have suggested that in such cases individuals fall into the trap of routinely carrying out their work without challenging assumptions or questioning the consequences of what they are doing ("involuntary automaticity" - Toft and Mascie-Taylor, 2005) In such cases organisational learning throughout the system is inhibited and the ability to adapt and learn from failure results in patterns of negative reinforcement which, in 
turn, act as a barrier to change (Tucker and Edmondson, 2003).

\section{Discussion and future research}

The analysis presented in the paper has shown that there are advantages in analysing hospital-based infection outbreaks from a system's perspective. Many of the issues that have been discussed have not been researched within the patient safety literature in much depth, particularly organisational phenomena (Waterson, 2008). The use of a systems ergonomics analysis facilitates a consideration of a wide range of issues which go beyond the current focus on individual levels of analysis (e.g., behavioural interventions in the form of hand washing campaigns). There is a need for much further investigation of the social, organisational and managerial aspects of infection outbreaks (Cole, 2008; Griffiths, Renz and Rafferty, 2008). Future research should, for example, establish the extent that management culture and behaviour have upon infection outbreaks. This work needs to carried out in tandem with evaluations of the impact of other initiatives that target other system levels (e.g., health care professionals and infection control teams). Without such studies there is a danger that researchers and practitioners gain at best a partial view, with the added result that the design of appropriate interventions will result in partial success, or at worse fail to achieve their objectives.

The process of identifying cross-level and whole-system provides a conceptual frame of reference that could serve as the basis for more focused empirical studies. In particular, future work should aim to follow the trend of recent work in organisational behaviour of using multi-level modelling techniques to unpick cross system (meso-) level relationships. This trend shows some promise and has already been used within health care ergonomics to understand the causes of medical errors (Karsh and Brown, in press) and factors determining the acceptance of electronic medical record systems (Greenhalgh et al., 2008). In addition, the analysis presented within the paper could be compared and contrasted with alternative models within systems ergonomics (e.g., resilience engineering). This could be achieved, for example, by building simulated computer models of infection control practices and comparing the results from models with hospital-derived data (Brailsford and Schmidt, 2003; Leveson et al., 2006). 


\section{References}

Allegranzi, B. Storr, J., Dziekan, G., Leotsakos, A., Donaldson, L. and Pittet, D. (2007), The first global patient safety challenge "Clean Care is Safer Care" from launch to current progress and achievements. Journal of Hospital Infection, 65 (supplement 2): 15 .

BBC Panorama (2008), How Safe is Your Hospital? (Broadcast on $27^{\text {th }}$ April, 2008), (available at:

http://www.bbc.co.uk/mediaselector/check/player/nol/newsid_7370000/newsid_7371 100 ?redirect=7371116.stm\&news $=1 \&$ nbram $=1 \&$ nbwm $=1 \&$ bbram $=1 \& b b w m=1$ accessed $28^{\text {th }}$ April, 2008)

Bean, G. and Hood, C. (2006), Have targets improved performance in the English NHS? British Medical Journal, 32, 419-422.

Beishon, J. and Peters, G. (1976, Eds.), Systems Behaviour (2 ${ }^{\text {nd }}$ Edition). Milton Keynes: Open University Press.

Brailsford, S. and Schmidt, B. (2003), Towards incorporating human behaviour in models of health care systems: An approach using discrete event simulation. European Journal of Operational Research, 150, 19-31.

Cartwright, S. and Cooper, C.L. (1993), The psychological impact of merger and acquisition on the individual: a study of building society managers. Human Relations, $46,3,327-347$.

Cole, M. (2008), HCAIs: challenging the assumptions. British Journal of Healthcare Management, 14, 376-381.

Department of Health (2001), Learning from Bristol. The Report of the Public Inquiry into children's heart surgery at the Bristol Royal Infirmary1984-1995. London: The Stationary Office.

Duerden, B. (2008), Tackling healthcare associated infections in the NHS - progress so far. British Journal of Infection Control, 9, 4-7. 
Genaidy, A.M., Sequeira, R., Rinder, M.M. and A-Rehim, A.D. (2008), Determinants of business sustainability: An ergonomics perspective. To appear in Ergonomics.

Greenhalgh, T., Strammer, K, Bratan, T., Byrne, E., Mohammed, Y. and Russell, J. (2008), Introduction of shared electronic records: multi-site case study using diffusion of innovation theory. British Medical Journal, 337:a1786.

Griffiths, P., Renz, A. and Rafferty, AM. (2008), The impact of organisation and management factors on infection control in hospitals: a scoping review. Kings College, London.

\section{(http://www.kcl.ac.uk/content/1/c6/04/08/39/Infectioncontrolreport.pdf,} (accessed $15^{\text {th }}$ September, 2008).

The Guardian (2007), Deadly superbug infections widespread in UK hospitals, says expert. The Guardian newspaper, October $11^{\text {th }} 2007$.

Hackman, J.R. (2003), Learning more by crossing levels: evidence from airplanes, hospitals, and orchestras. Journal of Organizational Behaviour, 24, 905-922.

Healthcare Commission (2006), Investigation into outbreaks of Clostridium difficile at Stoke Mandeville Hospital, Buckinghamshire Hospitals NHS Trust. (http://www.healthcarecommission.org.uk/_db/_documents/Stoke_Mandeville.pdf (accessed $8^{\text {th }}$ April 2008)

Healthcare Commission (2007), Investigation into outbreaks of Clostridium difficile at Maidstone and Tunbridge Wells NHS Trust.

(http://www.healthcarecommission.org.uk/_db/_documents/Maidstone_and_Tunbridg e_Wells_investigation_report_Oct_2007.pdf (accessed $8^{\text {th }}$ April 2008).

Healthcare Commission (2008) Learning from Investigations (http://www.healthcarecommission.org.uk/_db/_documents/Learning_from_investigat ions.pdf (accessed 17th September 2008). 
Hollnagel, E., Woods, D. D., and Leveson, N. (Eds.) (2006). Resilience Engineering: Concepts and Precepts. London: Ashgate.

House, R., Rousseau, D.M. and Thomas-Hunt, M. (1995), The meso paradigm: a framework for the integration of micro and macro organizational behaviour. Research in Organizational Behaviour, 17, 71-114.

Huggonet, S., Harbath, S., Sax, H., Duncan, RA. and Pitter, D. (2004), Nursing resources: a major determinant of nosocomial infection? Current Opinion in Infections Diseases, 17, 4, 329.

Karsh, B. (2006). Meso-ergonomics: a new paradigm for macroergonomics research. Proceedings of the International Ergonomics Association 2006 Congress.

Karsh, B-T. and Brown, R. (in press) Macroergonomics and patient safety: the impact of levels on theory, measurement, analysis and intervention in medical error research. To appear in Applied Ergonomics.

Kiessling, T., Harvey, M. and Heames, J.T. (2008), Acquisition issues. Journal of Leadership and Organizational Studies, 14, 4, 287-302.

Leveson, N., Dulac, N., Zipkin, D., Cutcher-Gerschenfeld, Carroll, J. and Barrett, B. (2006), Engineering resilience into safety critical systems. In E. Hollnagel, D.D. Woods and N. (Eds.) (2006). Resilience Engineering: Concepts and Precepts. London: Ashgate.

Leveson, N., Dulac, N., Marais, K. and Carroll, J. (2009), Moving beyond normal accidents and high reliability organizations: A systems approach to safety in complex systems. Organisation Studies, 30, 02-03, 227-249.

Mitleton-Kelly, E. (1998, Eds.), Proceedings of the Organisations as Complex Evolving Systems Conference, Warwick, UK: University of Warwick and London School of Economics and Political Science. 
National Audit Office (2000), The management and control of hospital acquired infections in acute NHS trusts in England.

http://www.nao.org.uk/publications/nao_reports/9900230.pdf (accessed October 1st 2008).

Optner, S.L. (1973), Systems Analysis. Harmondsworth: Penguin Books.

Parker, S. K. and Wall, T. D. (1998). Job and Work Design: Organizing Work To

Promote Well-Being and Effectiveness. Sage Publications: California.

Perrow, C. (2007), The Next Catastrophe. Princeton: Princeton University Press.

Rasmussen, J. (1997), Risk management in a dynamic society: a modelling problem. Safety Science, 27, 183-213.

Reason, J. (1995), A systems approach to organizational error. Ergonomics, 38, 1708 1721

Singleton, W.T., Easterby, R.S. and Whitfield, D. (1967, Eds.), The Human Operator in Complex Systems. London: Taylor and Francis.

Toft, B. and Mascie-Taylor, H. (2003), Involuntary automaticity: a work-system induced risk to safe health care. Health Services Management, 18, 211-216.

Tucker, A. and Edmondson, A. (2003). Why hospitals don't learn from mistakes: organizational and psychological dynamics that inhibit system change. California Management Review, 45, 2, 1-18.

Turner, B.A. (1978), Man-Made Disasters. London: Wykeham Publications.

Van Maanen, J. and Barley, S. (1985), Cultural organizations: fragments of a theory. In P. Frost, L. Moore, M. Louis, C. Lundberg and J. Martin (Eds.), Organizational

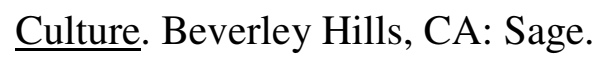


Vaughan, D. (1996), The Challenger Launch Decision: Risky Technology, Culture and Deviance at NASA. Chicago: Chicago University Press

Vicente, K.J. and Christoffersen, K. (2006), The Walkerton E. Coli outbreak: a test of Rasmussen's framework for risk management in a dynamic society. Theoretical Issues in Ergonomics Science, 7, 2, 93-112.

Waterson, P.E. (2008), Taking stock of the systems approach to patient safety. In S. Hignett, B. Norris, K. Catchpole, A. Hutchinson and S. Tapley (Eds.), Improving Patient Safety: Proceedings of the IPS Conference 2008. Ergonomics Society.

Weick, K.E. and Sutcliffe, K.M. (2003), Hospitals as cultures of re-enactment: a reanalysis of the Bristol Royal Infirmary. California Management Review, 45, 2, 73-84.

West, E. (2000), Organisational sources of safety and danger: sociological contributions to the study of adverse events. Quality and Safety in Healthcare, 9, 120126.

West, M.A., Borrill, C., Dawson, J., Scully, J., Carter, M., Anelay, S., Patterson, M. and Waring, J.(2002), The link between the management of employees and patient mortality in acute hospitals. International Journal of Human Resource Management, $13,8,1299-1310$.

Wood, S. and Wall, T.D. (2002), Human resource management and business performance. In P.B. Warr (Ed.), Psychology at Work ( $5^{\text {th }}$ Edition). Harmondsworth: Penguin Books.

Zohar, D. (2000), A group-level model of safety climate: Testing the effect of group climate on microaccidents in manufacturing jobs. Journal of Applied Psychology, 85, 587-96. 
Table 1: Summary timeline of infection outbreaks at Maidstone and Tunbridge Wells NHS Trust

\begin{tabular}{|l|l|}
\hline \multicolumn{1}{|c|}{ Time Period } & \multicolumn{1}{c|}{ Event } \\
\hline April 2000 & Trust established following merger between two other local NHS Trusts \\
\hline 2001/2-2005 & $\begin{array}{l}\text { High turnover of senior managers and period of organisational stability } \\
\text { (HC, 7) }\end{array}$ \\
\hline $\begin{array}{l}\text { October 2005 - } \\
\text { September 2006 }\end{array}$ & $\begin{array}{l}\text { More than 500 patients developed the infection, 60 patients estimated to } \\
\text { have died due to } C \text {. difficile infection. }\end{array}$ \\
\hline Before 2005 & $\begin{array}{l}\text { Trust has a high level of infection with } C \text {. difficile but no one in the trust } \\
\text { or local health authority was aware of this }\end{array}$ \\
\hline Autumn 2005 & $\begin{array}{l}\text { Number of patients infected doubles. Approximately 150 patients } \\
\text { affected, a number of whom died as a result of the infection. (first } \\
\text { outbreak - 7) }\end{array}$ \\
\hline April - September 2006 & 258 patients in total affected \\
\hline Beginning 2006 & Number of newly infected patients declines. \\
\hline April 2006 & $\begin{array}{l}\text { Trust recognises it has a major outbreak and reports this to strategic } \\
\text { health authority and health protection unit. (second outbreak - 7) }\end{array}$ \\
\hline April 2007 & $\begin{array}{l}\text { Healthcare Commission finds unacceptable examples of the use of } \\
\text { contaminated equipment (HC 8) }\end{array}$ \\
\hline October 2007 & Healthcare Commission Report published. \\
\hline
\end{tabular}




\section{Figure 1: Rasmussen's (1997) model of risk management within sociotechnical systems}

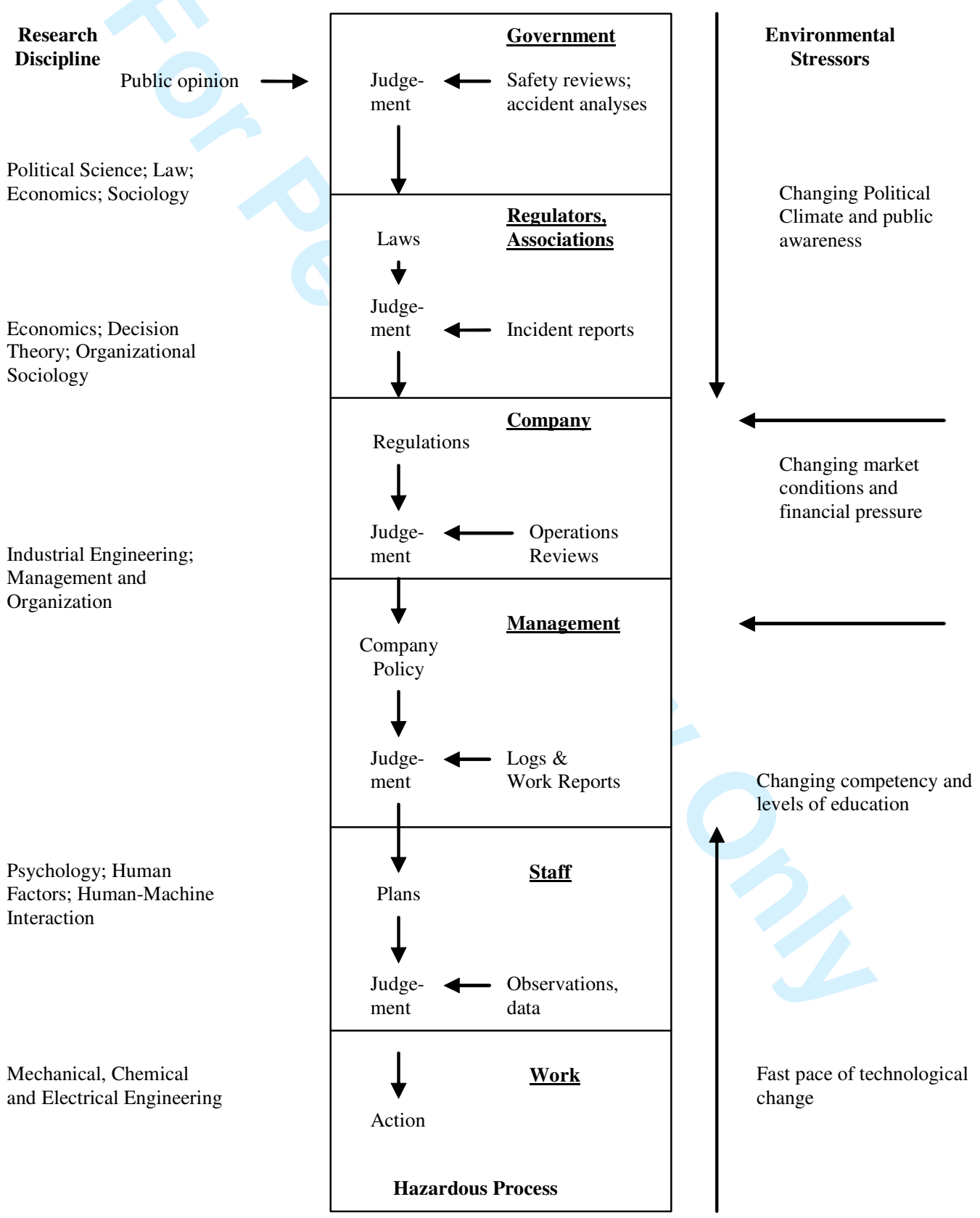


Figure 2 (a): Systems framework and outbreak contributory factors

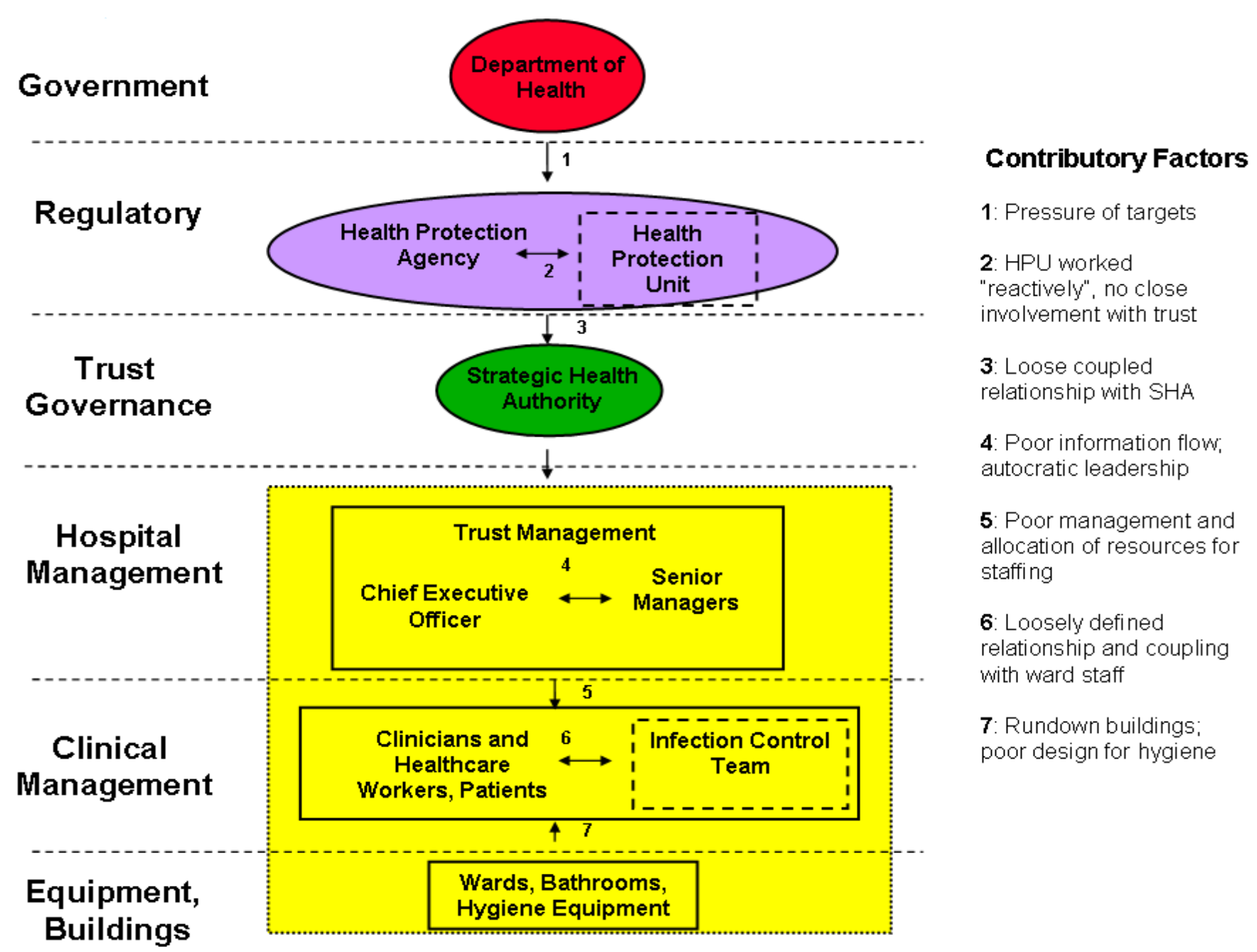


Figure 2 (b): System cross-level relationships

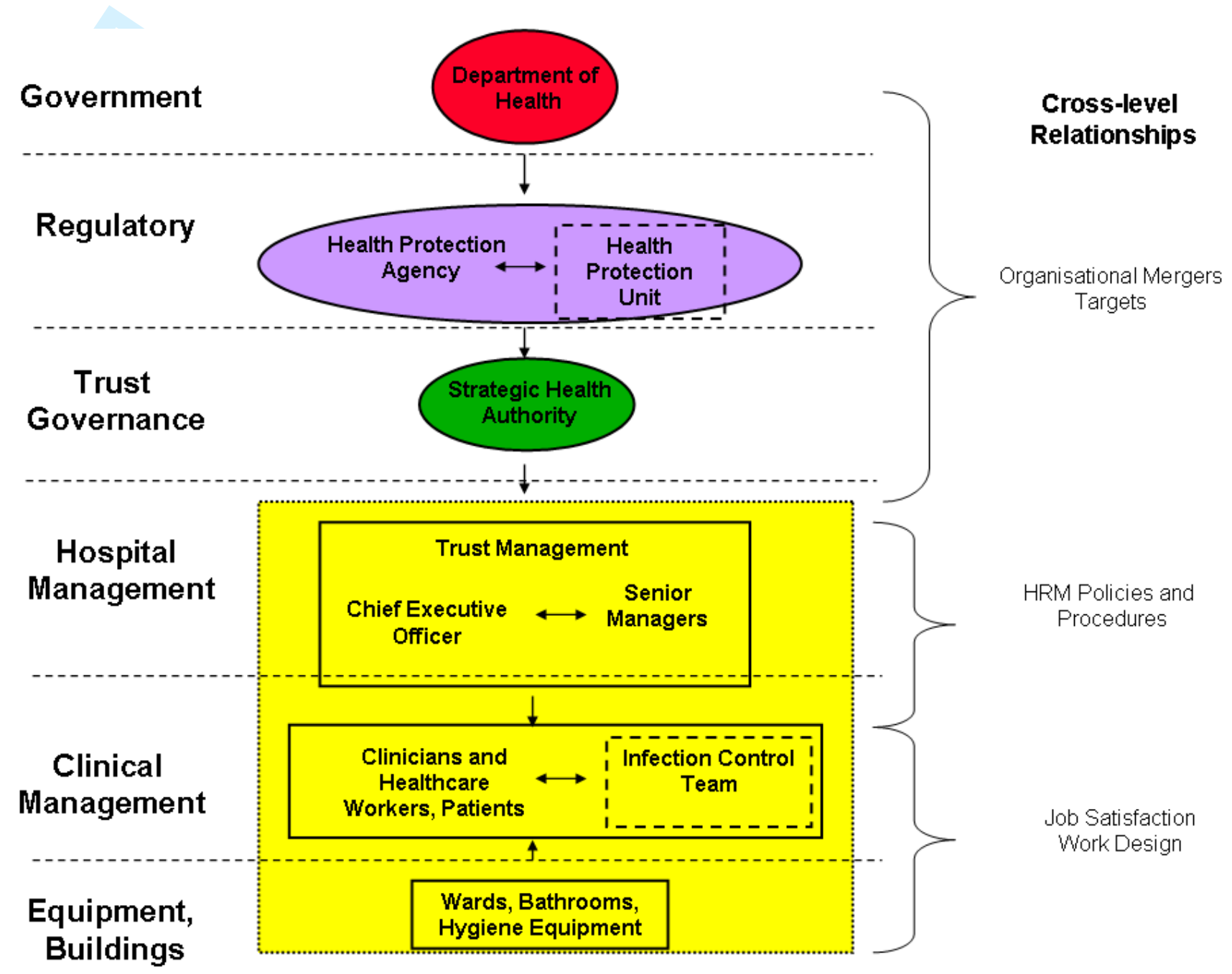

URL: http://mc.manuscriptcentral.com/terg E-mail: ergonomics@tandf.co.uk 
Figure 2 (c): Whole system relationships

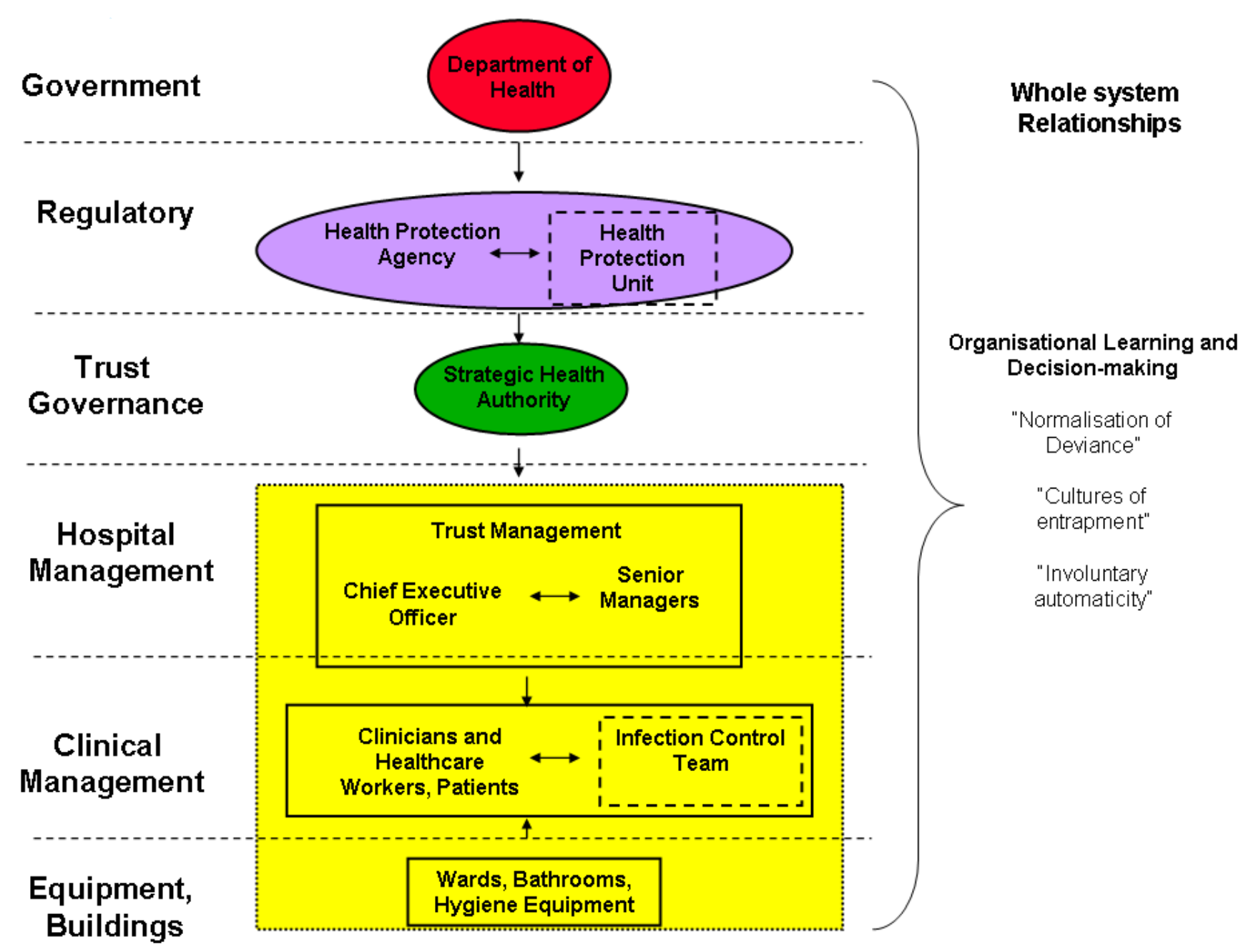

